\title{
REVITALIZACIÓN SINDICAL EN ARGENTINA: EL CASO DEL SUBTE ${ }^{1}$
}

\section{TRADE UNION REVITALIZATION IN ARGENTINA: THE CASE OF SUBWAY}

\author{
Cora Cecilia Arias* \\ Paula Dinorah Salgado**
}

\section{RESUMEN}

Este artículo retoma y describe los debates académicos internacionales sobre "revitalización sindical". En particular, se ocupa de la recepción en las investigaciones en Argentina. Una vez puntualizada la situación teórica, se intenta trasladar la reflexión sobre ese concepto hacia una experiencia empírica particular: el caso de la organización de base de los trabajadores de subterráneos de la ciudad de Buenos Aires. El objetivo es poner en debate las potencialidades analíticas de la postura teórica problematizada.

PALABRAS CLAVE: ARGENTINA * SINDICATOS * REVITALIZACIÓN SINDICAL * GRUPOS DE INTERESES * TRABAJADORES DEL SUBTERRÁNEO

\section{ABSTRACT}

This paper set out and describes the international scholar's debates about "trade union revitalization". Particulary, it addresses the usage of the concept in Argentinian research. After stating the theoretical question, a particular empirical experience is analyzed: the case of the rank-and-file organization of the subway workers of Buenos Aires. The aim is to debate on analytical potentialities of tackled theoretical standpoints.

KEYWORDS: ARGENTINA * TRADE UNIONS * TRADE UNION REVITALIZATION * INTEREST GROUPS * SUBWAY WORKERS

$1 \quad$ Una versión preliminar de este trabajo fue presentada en la 5ta Jornada de Jóvenes Investigadores (Arias y Salgado, 2009).

Instituto de Investigaciones Gino Germani, Facultad de Ciencias Sociales de la Universidad de Buenos Aires.

coracearias@gmail.com
** Instituto de Investigaciones Gino Germani, Facultad de Ciencias Sociales de la Universidad de Buenos Aires. pauladsalgado@yahoo.com.ar 


\section{INTRODUCCIÓN}

El presente artículo ${ }^{2}$ está dirigido a analizar el accionar sindical de las últimas décadas en distintos países, reflexionando en torno a las estrategias desplegadas y a las teorizaciones que dan cuenta de estas. El objetivo específico es intentar desguazar la multiplicidad de procesos que se imbrican en el concepto de revitalización sindical y cuestionar su pertinencia, para el análisis del caso del Subterráneo de Buenos Aires, Argentina.

Las primeras menciones sobre revitalización sindical nacen como resultado de la necesidad de articular nuevas acciones para palear la caída de las tasas de afiliación en diversas partes del mundo. Según Phelan (2008), el sindicalismo mundial está perdiendo influencia, no solo en áreas que le han concernido tradicionalmente como salarios, extensión de jornada $y$ condiciones de trabajo, sino también en lo relativo a su capacidad de promover objetivos más amplios, tales como democracia política, libertades civiles y justicia redistributiva. Ante esta situación, los sindicatos luchan por adaptarse a un nuevo contexto.

En este marco, la problemática de la revitalización sindical se ha convertido en terreno fértil para los debates sobre sindicalismo en la investigación en ciencias sociales. Se trata de resemantizar teorizaciones internacionales para reflexionar en torno al devenir de los sindicatos en la Argentina de los últimos tiempos. Desde 2003, comienzan a recuperarse los índices de ocupación, las demandas laborales vuelven a ocupar un lugar privilegiado en la escena pública, el trabajo es nuevamente debatido. Así, los sindicatos entran en escena, fundamentalmente, a la hora de reclamos salariales. Se produce una reactivación sindical.

Frente al axioma postulado por algunos autores, surgen estas interrogantes ¿qué significación adopta la denominada revitalización sindical? ¿qué procesos intenta visibilizar?

En estas páginas se intenta indagar sobre las potencialidades analíticas de situar la expe-

2 Agradecemos los comentarios y sugerencias del Dr. Pablo Ghigliani que sirvieron para articular las reflexiones de este trabajo. riencia del Cuerpo de delegados de subterráneos como exponente de la revitalización sindical. Para ello se procura aportar elementos que complejizan los análisis. Se hará particular hincapié en la relación existente entre la Unión Tranviaria Automotor (UTA), en tanto sindicato que representa legalmente a los trabajadores $y$ las construcciones de base opositoras ${ }^{3}$.

Se organizará esta exposición en tres partes: en primer término, se pasará revisión a los debates teóricos sobre revitalización sindical, a nivel internacional y nacional. En el segundo apartado, se pondrá en movimiento esas teorías en función del caso estudiado. Para ello, se describirá someramente los orígenes de la organización opositora a la UTA. Eso permitirá explorar una y otra organización y pensar, a partir de esa dicotomía, la revitalización sindical. Se finalizará, recuperando la indagación: ¿cuáles son los alcances y limitaciones de analizar el accionar obrero en términos de revitalización sindical?

\section{REVITALIZACIÓN SINDICAL: UN MAPA DE LA CUESTIÓN}

Promediando los años noventa, comienzan a desarrollarse diversas estrategias de revitalización o renovación sindical (trade union revitalisation, trade union renewal), con el propósito de fortalecer la entonces cuestionada y resquebrajada estructura sindical. Entre estas prácticas, ocupa un lugar central la afiliación de nuevos miembros. Otras medidas, como el impulso de estructuras sindicales horizontales, la realización de manifestaciones populares y el fomento de la construcción de coaliciones con otras organizaciones sociales, fueron inscritas dentro de este proceso (Haidar, 2009: 3). La revitalización sindical tiene sus principales exponentes en Inglaterra, Estados Unidos, Australia, Canadá, Nueva Zelanda y en una

$3 \quad$ En este artículo se adopta una estrategia metodológica eminentemente cualitativa, basada en entrevistas en profundidad. Esta metodología permite abordar el caso desde la perspectiva de los actores y por ello, acceder al conjunto de dimensiones analíticas de relevancia para reconstruir el proceso de organización de los trabajadores del Subterráneo. 
forma más incipiente, en Alemania y Holanda (Gall, 2009).

Actualmente, el concepto de revitalización sindical es aplicado en diversas partes del mundo para dar cuenta de distintos procesos relacionados con nuevas estrategias de accionar sindical. Los usos que se han hecho del concepto suelen diferir y por ello, se considera conveniente realizar una distinción a fin de echar luz sobre la heterogeneidad de procesos que son considerados dentro de esta corriente.

Algunos investigadores han utilizado el término para representar el inicio de una etapa ofensiva por parte del sindicalismo (Etchemendy y Collier, 2007: 6). Si bien, al respecto pueden alegarse cuestiones vinculadas a las perspectivas teóricas que cimentan cada análisis, se considera que las salvedades de cada caso deben ser explicitadas a fin de tener la certeza de estar abonando al mismo campo de estudio. Por esto, se ha propuesto rastrear en la literatura, los orígenes del concepto y sus diferentes utilizaciones con el objeto de aportar al esclarecimiento de la diversidad de procesos que están siendo considerados como indicadores de revitalización sindical.

¿Cuáles son estos distintos posicionamientos? En gran parte de los estudios realizados en países anglosajones -donde ha sido acuñado el término- el proceso de revitalización sindical se presenta como una estrategia impulsada por los sindicatos institucionalizados orientada al reposicionamiento en el campo político, frente a la crisis de representación en que se encontraban inmersos. El concepto es retomado por investigadores a fin de caracterizar este proceso y analizar, tanto el alcance como la efectividad de las estrategias en la consecución de sus objetivos.

De esta manera, para caracterizar la revitalización sindical se pueden enumerar las estrategias desplegadas que aparecen con mayor frecuencia en la literatura. Una de ellas se ha denominado "Modelo Organizacional" (Organising Model) y ha sido implementada en Gran Bretaña, Estados Unidos, Australia, entre otros países. Este supone la ejecución de cambios en la estructura sindical relacionados con la profesionalización y modernización (Hamann y Martínez, 2003) y con el fomento de la democracia interna (Fairbrother et ál., 2007). Este modelo se contrapone al sindicalismo de servicios, en tanto los recursos del sindicato, otrora destinados a la provisión de servicios a los miembros existentes, son transferidos hacia el reclutamiento de nuevos miembros (Phelan, 2007). El liderazgo y los líderes ocupan un nuevo rol en la organización (Fairbrother et ál., 2007), puesto de manifiesto a través de los cargos rentados (full-time officers) que son parte constitutiva de este modelo. Los "oficiales de tiempo completo" encarnan la tarea del reclutamiento y la organización de los trabajadores en el lugar de trabajo. La intención de lograr un aumento del involucramiento de los afiliados a través de esta estrategia ha sido cuestionada, ya que el incremento de la participación de los miembros aparece vinculado más estrechamente con el manejo y la necesidad de los líderes, que con el activismo de las bases. Quienes acuden en defensa del modelo, sostienen que los intereses de los miembros son variables y son los líderes quienes pueden articularlos para tomar decisiones estratégicas (Fiorito, 2004).

La construcción de coaliciones con otros actores de la sociedad civil (Phelan, 2007) es otra de las características que se ha dado en el modelo organizacional. En este sentido, los sindicatos son entendidos como "sujetos políticos”, que atienden intereses sociales y no solo lo concerniente al mundo del trabajo. De esta manera, buscan tomar distancia del pasado en el que aparecían meramente como actores económicos (Baccaro et ál., 2003).

Baccaro, Hamann y Turner (2003) distinguen dos perfiles relacionados con el incremento del activismo político: por un lado, el sindicalismo de movimiento social, orientado al activismo de base - estrechamente vinculado al modelo organizacional-y por el otro, el involucramiento institucional (social partnership), cuyos exponentes son Italia y Alemania. Este último, supone estrategias de tipo institucional como la injerencia en políticas estatales y la influencia sobre partidos políticos. Otro mecanismo consiste en la inserción de cláusulas que garanticen derechos básicos en materia 
laboral en acuerdos comerciales (trade agreements) (Phelan, 2007).

La solidaridad internacional (Phelan, 2007) y entre confederaciones (Hamann y Martínez, 2003) aparecen relacionadas a las diversas estrategias como objetivos ineludibles.

\section{REVITALIZACIÓN SINDICAL EN ARGENTINA: LA RECEPCIÓN DE LA CUESTIÓN}

Algunos estudios desarrollados a nivel local enfatizan el renovado protagonismo de los sindicatos en la arena de la negociación sindical. La estrategia viene dada por la preservación organizacional y los realineamientos sectoriales llevados a cabo en épocas hostiles al accionar de los sindicatos, en tanto el centro gravitacional de este proceso está puesto en la relación establecida con un gobierno "favorable a los intereses sindicales" (Etchemendy y Collier, 2007: 6). Desde esta perspectiva, el incremento de la negociación colectiva y de la movilización impulsada por los sindicatos, aparecen como muestras que bastan para proclamar un sindicalismo a la ofensiva.

Por su parte, Atzeni y Ghigliani interpretan este proceso en otro sentido. La reactivación de la negociación y el incremento de la movilización no alcanzan para anticipar un resurgimiento si no hay expresiones de "nuevas fuerzas organizativas, nuevas tácticas o nuevas actitudes por parte del trabajo organizado". El escenario sindical da pautas de la operatoria de "viejos mecanismos tripartitos de intercambio político" (2007: 12), fomentados por un gobierno que se enfrenta a un creciente estado de movilización de las bases, que pone en jaque a las conducciones tradicionales. Los autores concluyen observando que los signos de revitalización de las viejas prácticas sindicales no están indicando una renovación.

Para profundizar en el rol desplegado por el sindicalismo en la actual coyuntura, resulta imprescindible atender a las características del marco legal argentino en que se desenvuelven las relaciones sindicales. El criterio de unidad sindical ${ }^{4}$ establecido en nuestro país, marca

$4 \quad$ El sistema adoptado por la legislación argentina es el de unidad promocionada o unidad inducida. una diferencia sustancial y aporta otros elementos para analizar la revitalización sindical. Por un lado, sienta las bases para el desarrollo de un sindicalismo monopólico y por el otro, extiende el alcance del sindicato a todos los trabajadores que se hallan bajo su área de influencia convencional, estén o no afiliados. Dicho alcance se expresa tanto en la aplicación de los aumentos salariales acordados en negociaciones paritarias, como en la retención de las llamadas "cuotas de solidaridad"5.

La diferencia señalada aparece en forma clara al analizar el origen de los recursos de los sindicatos: aquellos que han desplegado estrategias de revitalización sindical en otros países, dependen de los aportes de los trabajadores para su supervivencia, de allí que el incremento de la afiliación figure como uno de los objetivos centrales. En el caso argentino, en cambio, los recursos de los sindicatos con reconocimiento

Implica que solo una organización sindical —concretamente la más representativa según lo que indica la ley - puede detentar la personería gremial. Al respecto, la ley 23551 en su artículo 25 establece:

La asociación que en su ámbito territorial y personal de actuación sea la más representativa, obtendrá personería gremial, siempre que cumpla con los siguientes requisitos:

a) Se encuentre inscripta de acuerdo a lo prescripto en esta ley y haya actuado durante un período no menor de seis (6) meses;

b) Afilie a más de veinte por ciento (20\%) de los trabajadores que intente representar.

c) La calificación más representativa se atribuirá a la asociación que cuente con mayor número promedio de afiliados cotizantes, sobre la cantidad promedio de trabajadores que intente representar (Ley 23551 de Asociaciones Sindicales).

$5 \quad$ En este sentido, la ley 14250 en su artículo 9 establece que:

La convención colectiva podrá contener cláusulas que acuerden beneficios especiales en función de la afiliación a la asociación profesional de trabajadores que la suscribió.

Las cláusulas de la convención por las que se establezcan contribuciones a favor de la asociación de trabajadores participantes, serán válidas no sólo para los afiliados, sino también para los no afiliados comprendidos en el ámbito de la convención (Ley 14250 de Convenciones Colectivas del Trabajo). 
legal ${ }^{6}$ no provienen exclusivamente de los aportes de los trabajadores. De este modo, la crisis de representación no tiene un impacto económico para el sindicalismo institucionalizado. Es necesario tener presente este punto para analizar la aplicabilidad del proceso de revitalización sindical en la coyuntura argentina.

Algunos de los estudios que abordan la revitalización sindical enfocan el proceso desde las cúpulas sindicales. La organización y movilización de las bases, incluso allí donde se manifiestan en claro cuestionamiento, a las instituciones sindicales, no cobra mayor relevancia en gran parte de la bibliografía. Tal como señalan Atzeni y Ghigliani, si bien el término revitalización sindical está siendo utilizado para describir $y$ analizar estrategias llevadas a cabo por los sindicatos y para indicar la recuperación de fuerzas del movimiento obrero:

... continúa incrustado en una mirada unilateral y mayormente pesimista del trabajo y de los trabajadores como potenciales agentes de cambio social, una mirada que consecuentemente minimiza la importancia de los trabajadores $y$ los sindicatos como actores en la arena política (2008: 1).

En este sentido, Santella advierte que "la revitalización de las instituciones sindicales no equivale a la recomposición de la clase trabajadora como sujeto de transformación histórica" (2008: 14). Sin embargo, el concepto no excluye necesariamente los procesos de organización de base. La escasa producción teórica en ese sentido, posiblemente se deba a las realidades de otras latitudes en las que el concepto está ampliamente difundido.

En un intento por enriquecer la mirada y complejizar los disímiles análisis, se plantean las preguntas de investigación en este artículo: ¿puede pensarse la construcción gremial de los trabajadores de subterráneo como exponente de revitalización sindical?, ¿qué sucede con los

$6 \quad$ El caso que se analiza en el presente artículo resulta excepcional en este sentido, ya que al no contar con personería gremial no dispone de más recursos que el aporte voluntario de los trabajadores. conceptos teóricos cuando nos atrevemos a "aplicarlos" en la empiria?

\section{LA EXPERIENCIA DEL CUERPO DE DELEGADOS}

DEL SUBTE: ¿̨REVITALIZACIÓN SINDICAL O CUESTIONAMIENTOS A LA REPRESENTACIÓN TRADICIONAL?

\section{El hostigamiento y la persecución de la Empresa fueron moneda corriente y no hubo quién representara el dolor del Subte \\ (Comunicado de Metrodelegados).}

No es azarosa ni fortuita la elección de la experiencia del Cuerpo de delegados de subterráneos para reflexionar e interrogarse acerca de lo que para algunos representa un axioma: la revitalización sindical en la Argentina de los últimos años. A continuación, se justificará la decisión teórico-metodológica. En primer término, es un caso que forma parte de un trabajo previo de investigación y por ende, se cuenta con la suficiente información empírica para fundar los argumentos. Por otro lado, porque la experiencia en el subte es un caso paradigmático, en el que se basa la amplia mayoría de la bibliografía a la hora de celebrar la reactivación sindical. Además, esta experiencia es un fiel ejemplo del regreso del conflicto hacia el lugar de trabajo que se ha venido suscitando en Argentina desde el año 2003 y en ese sentido, resulta muy atractivo para reflexionar sobre problemáticas sindicales.

En una primera instancia, el objetivo en el presente apartado es describir brevemente la organización del Cuerpo de delegados del subte ${ }^{7}$. Se hará particular hincapié en la relación establecida con el sindicato madre, la UTA. Esto permitirá luego, retomando las características de la revitalización sindical descritas anteriormente, esbozar alguna suerte de respuesta al interrogante que guía este artículo: ¿qué potencialidades analíticas reviste situar la experiencia

$7 \quad$ A estos fines nos basaremos en entrevistas en profundidad realizadas a delegados y trabajadores en el período 2006-2009, registros de campo, artículos de diarios diversos y documentos de los protagonistas. No daremos los nombres de los entrevistados para proteger su identidad. 
del Cuerpo de delegados de subterráneos como exponente de la revitalización sindical?

\section{A) RECAPITULANDO LOS ORÍGENES DE LA ORGANIZACIÓN}

En un trabajo anterior (Abal et ál., 2008) se planteaba que la organización de base del Cuerpo de delegados del subte - hoy Asociación Gremial de los Trabajadores de subte y premetro (AGTSyP) - podía analizarse a partir de la idea de una "doble clandestinidad" hacia el sindicato. Se justificará esta afirmación desde sus características más relevantes.

Este caso posee una serie de especificidades que lo vuelven muy particular. En primer lugar, vale recordar que los subtes se encuadran dentro de la lógica de los servicios, elemento que se potencia en virtud de su exclusividad como medio de transporte. A esto hay que sumarle que se estima que utilizan ese servicio alrededor de un millón y medio de personas diariamente. En consecuencia, se constituye en un sector sumamente sensible $y$ de alta visibilidad. Este dato permite explicar en parte, la efectividad de las medidas de fuerza adoptadas por los trabajadores.

La empresa Metrovías accedió a la concesión de los subterráneos de la Ciudad de Buenos Aires en 1994. Hasta mediados de 1992, los subtes porteños administrados por el Estado contaban con cerca de 4500 trabajadores, que se fueron reduciendo hasta alcanzar la cifra de 1500 , vía las modalidades de despidos y retiros voluntarios. Dentro del conjunto de estos trabajadores que fueron desafectados se cuentan muchos de quienes habían sido delegados y activistas $y$ con ellos, se perdió parte de la memoria y de la experiencia tanto sindical como organizativa.

El proceso concesionario - al igual que gran parte de las políticas privatizadoras acaecidas en Argentina, en la década del 90, signadas por una racionalidad neoliberal- contó previamente con un proceso de "saneamiento" en el marco del cual se dieron las reducciones de plantilla recién mencionadas. Una vez que el traspaso a manos privadas fue consumado, la nueva empresa procedió a incorporar nue-

8 Comparten esta situación trabajadores de call center, encuestadores, entre otros. vos trabajadores (muchos de ellos jóvenes que luego conformarían el Cuerpo de delegados) y a tercerizar muchas de las actividades que antes pertenecían a la misma empresa, tales como seguridad, limpieza, talleres de reparación, etc. ${ }^{9}$.

Con la toma de posesión de la nueva concesionaria, muchas de las condiciones de trabajo originales fueron alteradas (Vocos, 2007), entre ellas cabe destacar el incremento de la jornada laboral.

Ahora bien, mientras el capital avanzaba vorazmente $-y$ considerando el axioma foucaultiano: donde hay poder, hay resistencia (Foucault, 1983) - la organización empezaba a gestarse. La historia de esta particular comisión, se remonta a los tiempos del proceso de privatización de los subterráneos. Como ya se ha dicho, la gran mayoría de los actuales delegados ingresaron a la empresa cuando ya estaba en manos de Metrovías. Vale recordar que por aquellos años se acababa de vivir un proceso de reducción drástico de trabajadores, dejando un clima de temor en el colectivo. El entramado laboral quedó conformado entonces, por aquellos que venían desde la empresa estatal, un número significativo de nuevos trabajadores (rondaban los 500) y muchos que conformaban las plantillas de las empresas tercerizadas.

En este marco, en el que evidentemente los lazos entre los trabajadores habían desaparecido - o si existían, estaban muy deteriorados- las posibilidades de generar una organización en aras de la defensa de sus intereses eran escasas. A esto se suma un contexto de relaciones de fuerza sumamente desfavorables para el polo del trabajo, signado por las arbitrariedades del capital como norma, operando en la subjetividad de los trabajadores una gran sensación de desconfianza e indefensión (Arias y Haidar, 2008). Esto se expresa fuertemente en los testimonios de los delegados al describir los orígenes de la organización:

$9 \quad$ La tercerización trae aparejada una fuerte fragmentación de los colectivos de trabajo, en la medida en que cada sector responde a un empleador diferente, está representado por diferentes sindicatos $y$ por tanto, enmarcado por distintos convenios colectivos, lo que genera una enorme diferenciación en salarios y condiciones de trabajo entre unos $y$ otros. 
-Sí, había mucha persecución, porque si te llegaban a... se llegaban a enterar quiénes eran, adónde se reunían, esos compañeros volaban. Hubo algunos compañeros que fueron despedidos por sospechas, o por sospecharse de que eran integrantes, o iban a... a estas reuniones. Por eso era muy, muy complicado en las primeras épocas. Y se empezaba a hacer, inclusive sin hablar de política: invitar a una comida a la casa, un asado: empezar a hacerlo más desde el punto de vista social (Delegado de Metrovías).

¿Acaso había lugar para la articulación de lo colectivo? y ¿dónde estaba la UTA? Indudablemente, el proceso de organización debía originarse un paso más atrás, en la recomposición de los lazos sociales entre los propios trabajadores. En ese sentido, trabajaron estos "activistas" (para utilizar su propia denominación) al recrear actividades fuera del ámbito laboral, en un primer momento, orientadas a gestar relaciones mínimas entre trabajadores. Estas estrategias tenían al menos dos sentidos: por un lado, salir del ámbito laboral por el temor a las persecuciones y por el otro, generar esos vínculos sociales, que como se ve, exigían de las recomposiciones más elementales como la confianza entre compañeros.

Los orígenes de la organización, desde los relatos de sus protagonistas, llevan la impronta de lo clandestino: lo que primaba entre las sensaciones de estos trabajadores era el miedo, esa sensación que horada el lazo social, reduciéndolo a la mirada desconfiada hacia el compañero:

-Un día me pasó una cosa muy curiosa: había una movilización a Plaza de Mayo - que no me acuerdo por qué era- entonces yo fui. Voy caminando para la Plaza de Mayo, cuando estoy llegando me agarra algo en el brazo, me doy vuelta y era un compañero del laburo. Me dice: “¿adónde vas?". No - le digo- quedé de encontrarme con unas personas acá. Y le digo: "¿y vos adónde vas?". "No, yo también”. Le digo: "no me chamuyés. Vos venís a la movili- zación". "Sí". "Bueno, yo también". "No yo milité en un partido... que pin, que pan”. Bueno, era todo muy resguardado. Andábamos con mucho cuidado porque en donde te pescaban, te rajaban a la mierda (Delegado de Metrovías).

Una de las particularidades de esta experiencia es que la comisión interna de los subtes se encuentra enfrentada con la dirigencia del sindicato que tiene injerencia en la actividad, la UTA. Para los trabajadores de base, el sindicato es colocado como un enemigo en el mismo plano que la patronal y el Estado:

-Pero juntamente con eso, había que dar una pelea por limpiar el cuerpo de delegados. Porque la mayor parte de los delegados eran de la burocracia. Así que había varios frentes de lucha: uno, el principal, era luchar contra el escepticismo y la desmoralización de los compañeros, que de a poco los íbamos levantando. Segundo, contra el aparato que la burocracia había logrado reconstituir. Con algunas grietas, como por ejemplo las de acá. Y la otra, el omnipresente poder del Estado y de la burocracia y de la empresa... (Delegado de Metrovías).

Entre las primeras estrategias de esta organización se encontraba la de disputar la estructura del Cuerpo de delegados, dado que como se expresa en la cita, este sindicato es visto como un aliado de la empresa. El proceso que comienza con la elección de uno de sus delegados en 1996, logra la totalidad de los delegados de la Junta interna y culmina hoy - plebiscito mediante - con la conformación de la AGTSyP, junto al pedido de reconocimiento como sindicato paralelo por parte del Ministerio de Trabajo. El escenario queda entonces planteado del siguiente modo: si bien la UTA cuenta con la representación a nivel de la actividad, es decir, tiene entre otras la potestad de firmar convenios colectivos $y$ de negociar al nivel de la Junta interna de los subterráneos en su totalidad, prácticamente no tiene intrusión. El grado de oposición y enfrentamiento entre el Cuerpo de delegados y la línea oficial de la UTA 
suele ser una complicación adicional a la hora de los conflictos y las negociaciones. Un ejemplo puede observarse en los resonantes conflictos que se han producido en el subte en los últimos años, a partir de las demandas de reducción de la jornada, aumentos salariales, impedimento de la instalación de máquinas expendedoras de boletos, la incorporación al convenio del transporte de los trabajadores tercerizados, etc. Estos conflictos llegaban rápidamente a instancias del Ministerio de Trabajo en virtud de su condición de bien público, generándose una difícil situación. En varias ocasiones se firmaba la conciliación obligatoria entre los representantes de UTA y de Metrovías, con la oposición de los delegados de base. En consecuencia, pese al dictado de conciliación, se continuaba con las medidas de fuerza.

Así, la recomposición del lazo social, esa búsqueda desde menos que cero hacia la organización, es una ruta deliberada y escarpada. En el origen, las primeras miradas de los activistas pretendían el reconocimiento, encontrar en el otro el rastro de la trasgresión $y$ se encontraron:

-... mirá yo desde que entré acá formé parte de lo que era el activismo, que se había denominado el activismo en ese momento, tratando de organizar a los compañeros... Ya había algunos compañeros que desde la clandestinidad estaban tratando de organizar algo, $y$ bueno... Después yo fui conociendo a algunos - a medida que iba también haciendo mis propias actividades- $-y$ ese activismo dio como resultado el cuerpo de delegados actual. La mayoría de los compañeros son activistas de la primera hora (Delegado de Metrovías).

Ese hallazgo fue el primer paso, encontrar a otros discutiendo lo mismo, queriendo también arrancarle al miedo su lugar mediador. Pero ese querer recomponer en el trabajo los lazos de los de igual condición, no es cosa sencilla, exigía y exige, un trabajo de militancia:

—Finalmente nos fuimos organizando; partidos de fútbol, algunos almuerzos...; qué sé yo. Teníamos compañeros que les gustaba la música clásica, me puse a estudiar cuestiones de música clásica para poder hablar con ellos (Delegado de Metrovías).

El rol del activista, del militante, ha sido en esta experiencia fundamental para la organización. Algunos de ellos provenientes de partidos políticos, algunos no $y$ todos con el horizonte de lo colectivo en la construcción de las referencias comunes, $y$ las del otro (o los otros) a quienes se reconoce en frente.

Resta mencionar un elemento que se considera fundamental en el análisis de estas experiencias. Esto se refiere al hecho nada menor que desde su origen, la organización de la comisión de delegados de Metrovías ha ido paulatinamente alcanzando los objetivos que se vino trazando desde entonces. En este sentido, cabe mencionar el retorno a la jornada de seis horas de trabajo que se logró en 2004, reiterados incrementos salariales que posicionaron a estos trabajadores entre los de salarios más altos. Además, gradualmente se viene logrando incorporar al convenio colectivo de la UTA a los trabajadores tercerizados. Estas conquistas ponen de manifiesto no solo la fuerza que esta organización ha conseguido, sino también y más trascendente quizás, el grado de solidaridad generado entre los trabajadores, que es en definitiva la aspiración máxima del sindicalismo, al menos del sindicalismo entendido como estos trabajadores lo hacen.

Hasta aquí la breve caracterización de esta experiencia, particularmente en torno a aquellas cuestiones que se retomarán en el apartado que sigue, a fin de hacerlas dialogar con los preceptos de la revitalización sindical.

\section{B) LA REVITALIZACIÓN SINDICAL VIS À VIS LA EXPERIENCIA DE LA ORGANIZACIÓN EN LOS SUBTES}

Las discusiones sobre revitalización sindical que se referencian más arriba, acuerdan en señalar algunos preceptos descriptores de esa situación. A los efectos de intentar responder la interrogante guía, se elegirán dos de ellos —no por ser los más importantes ni los únicos, 
sino porque abonan en esta reflexión- para analizar ¿qué valencias adquieren en este caso de investigación?

\section{LAS ESTRATEGIAS DE AUMENTO DEL NÚMERO DE AFILIADOS}

Los debates internacionales sobre revitalización sindical, coinciden al ubicar el aumento en el número de afiliados como una de las estrategias más sobresalientes de los sindicatos en ese contexto. Se denota que la mayoría de los casos investigados por esa literatura tienen características, sobre todo puntos de partida, que difieren de nuestra situación nacional. Es decir, el proceso de debilitamiento de la acción sindical a nivel mundial estuvo acompañado de una fuerte desafiliación. No obstante, recuperando una advertencia ya establecida por Atzeni y Ghigliani (2008), las estadísticas indican que en Argentina la tasa de afiliación, aún en los momentos de mayor debilidad, se mantuvo estable.

Ahora bien, ¿qué se oculta tras el velo de los números porcentuales? Por un lado, las amplias mayorías de trabajadores desocupados, informales y precarizados que aparecen como "no sindicalizables"10, pertenecientes a la "non union zone" (Haiven, 2006); por otro lado, las formas que adopta la afiliación (la cual se convierte en compulsiva en muchos casos), como así también su contenido (se refiere principalmente a los servicios prestados por los sindicatos, en particular a la obra social).

¿Cuáles son las políticas de la UTA en este sentido? Se insiste, la UTA continúa siendo el sindicato que legalmente representa a los trabajadores de subterráneos y la construcción de la AGTSyP, esta solo actúa de hecho y no de derecho, con las consecuencias que eso conlleva. En el transcurso del trabajo de campo, al solicitar a los entrevistados que relaten su entrada a la empresa y su primer vínculo con el sindicato, este aparece desdibujado y con una importancia menor ${ }^{11}$. El siguiente extracto de una de las entrevistas lo demuestra:

10 La central opositora (Central de Trabajadores Argentinos, CTA) incorpora a estos trabajadores en sus filas; sin embargo, no podemos considerarlo, ya que aún, no tiene reconocimiento gremial.

11 Es necesario establecer una diferenciación entre los trabajadores sin ningún tipo de militancia anterior y los activistas que tenían una relación distinta con lo sindical.
-... no, yo entré acá y ni idea de los sindicatos y esas cosas, era mi primer laburo. No sé si había delegado antes que estuviera Beto, yo ni idea. Y me dijeron que estaba afiliado porque firmé una cosa, no sé, en el momento del contrato con Metrovías te daban otro papel y no te decían mucho. Uno creía que era por la obra social y por eso firmaba, pero ni idea del sindicato, nadie te explicaba nada... (Trabajador de Metrovías).

Estas palabras $-y$ se podría citar muchas más que se dirigen en el mismo sentido-, son una muestra del rol que juega la UTA en el ámbito del subte. Los precursores de la revitalización plantean como una de las estrategias, ampliar el reclutamiento más allá de los familiares de los miembros de las bases (Fairbrother, 2005). La política adoptada por la UTA, sin embargo, apuntaba al fortalecimiento del aparato burocratizado y no a captar la diversidad de necesidades del conjunto de trabajadores. Dice un delegado al respecto:

- Hicieron un acuerdo con la Empresa, hicieron ingresar un montón de gente del lado de UTA el último año, o sea que quedaron desocupados por cierre de líneas de colectivos del Gran Buenos Aires o que fueron fusionados $y$ gente quedó afuera. Todo esto o pariente de o hijo de todo aquel de UTA con la directiva de que vengan a confrontar de alguna forma en contra del Cuerpo de Delegados que venimos desde el 2000 para acá organizando... (Delegado de Metrovías).

¿Se referirán a esto los investigadores al describir la experiencia del subte como signo de revitalización sindical, o hará falta complejizar el análisis? Con esa intención, se suma un dato que surge de una denuncia realizada por el Cuerpo de delegados con respecto a los vínculos estrechos entre la UTA y Metrovías:

Una y otra vez, la sociedad UTA-Metrovías nos han tratado de estafar, resolviendo a espaldas de los trabajadores aumentos 
insuficientes, pérdidas de beneficios a cambio de recibir prebendas de todo tipo, como el 1\% de "aporte voluntario" que Metrovías realiza por cada trabajador No afiliado al sindicato UTA para compensar la ridícula cantidad de afiliados que cuenta esa organización (Comunicado de prensa del Cuerpo de delegados del subte) $)^{12}$.

Aunque no se pudo corroborar esta acusación, no resulta descabellada. Como consecuencia de esta $y$ otras querellas, desde principios de 2009 - momento en que los delegados de base decidieron conformar el sindicato paralelo-, se propuso un masivo proceso de desafiliación de la UTA. En oposición a aquella y mediante una política de acercamiento personal a cada trabajador que también va acompañada del ofrecimiento de servicios y beneficios, ha comenzado a producirse el éxodo hacia el nuevo gremio que pretende su reconocimiento legal.

\section{EL AUMENTO DE LA PARTICIPACIÓN A PARTIR DE MODIFICACIONES DE LA ESTRUCTURA INTERNA}

Otro de los factores señalados asiduamente en la bibliografía a la que se ha tenido acceso, hace referencia a las transformaciones a nivel institucional y organizativo que llevaron adelante los diferentes sindicatos, con el propósito de aumentar la cantidad y la calidad de la participación de sus miembros, poniendo en locución un discurso de democratización de las estructuras internas. Se trata de modificaciones intestinas, de instalación de dispositivos de horizontalidad, dando impulso a la profesionalización y la modernización de la organización (Hamann y Martínez Lucio, 2003).

¿Podemos decir que las políticas de la UTA se dirigieron en esa dirección? Su estructura interna está compuesta por el Congreso General de delegados, además existe un Consejo Directivo Nacional y las Juntas Ejecutivas Seccionales, el

Vale recordar aquí que la representación recae en el sindicato con mayor número de afiliados. Como la UTA abarca también a las líneas de colectivos, le permite mantener a la dirigencia actual el mando del sindicato.
Secretariado y la Comisión Revisora de Cuentas. Ahora bien, la elección de todos estos órganos se realiza por el sistema de lista completa, en distrito único y mediante el voto secreto $y$ directo de los afiliados. ¿Acaso estas restricciones legales no se traducen en constreñimientos a la participación ampliada y la renovación? Así relata esta situación un delegado:

—Dentro de la UTA es muy difícil pelear, porque vos no podés presentar lista opositora a ellos porque tenés que tener representación a nivel nacional. Nosotros somos Subte de la Ciudad de Buenos Aires. A todo eso tenés que salir a caminar todas las líneas del Buenos Aires, del conurbano $y$ del interior. Tener gente que tenga ganas de enfrentar a estos muchachos a nivel nacional en cada provincia. Los estatutos los votaron ellos para que sean ellos los únicos habilitados, aparte dentro de la lista que vos podés llegar a tener se dan todas las cosas aparte de tener que estar en las provincias, se da un porcentaje de la comisión directiva que vos tengas. Las listas sábanas Nacional tienen que ser gente que esté del mandato anterior o que haya estado, que haya sido dirigente dentro de la UTA sino tampoco (Delegado de Metrovías).

Ningún indicio permite inferir que las estrategias del sindicato que legalmente continúa representando a los trabajadores del subte se hayan dirigido hacia una democratización y apertura de sus estructuras. En una dirección contraria y erigiendo como uno de los clivajes fundamentales de oposición, la AGTSyP impulsa un discurso asambleario y de democracia interna ${ }^{13}$ :

13 No se ahondará en este artículo en las discusiones sobre democracia sindical, ya que no es el objetivo, solo se recupera estas palabras de Gramsci para una posible reflexión. El filósofo italiano analiza la experiencia de los Consejos de fábricas: "en toda fábrica, en todo taller hay un organismo constituido sobre la base de la representación (y no sobre la antigua base del sistema burocrático), el cual vela por la fuerza del proletariado, lucha contra el orden capitalista o ejerce el control 
- Lo que nosotros instalamos frente a la opinión pública es el método de la asamblea. Cada vez que nosotros salimos por los medios, los trabajadores deciden, la asamblea decide; la UTA levantó el paro y acá las asambleas no lo levantaron (Delegado de Metrovías). -... y no un gremio que habla de democracia cuando elige a colectiveros para presionar a cualquiera elegido por sus pares y que tenga la voz consensuada de sus mismos compañeros (Delegado de Metrovías).

Esta organización propone una verdadera apertura del sindicato, resignificando las estructuras desde un discurso basista, cuyo principal beneficio es la legitimidad lograda hasta ahora. Un ejemplo de ello se encuentra en su página web oficial "Metrodelegados":

Martes 10 hs en el hotel Bauen

Súmate al Cuerpo de Delegados!!! Todos los martes, a partir de las 10 hs, en el hotel BAUEN —Callao 360tienen lugar las reuniones del Cuerpo de Delegados del Subte. Te invitamos a participar activamente junto a los delegados de tu sector para mejorar el intercambio de ideas y la elaboración de propuestas que luego sean sometidas a la consulta de las respectivas ASAMBlEas (Comunicado del Cuerpo de delegados).

¿Cómo responde la UTA frente a las políticas adoptadas por los delegados opositores? ¿Hay posibilidades de renovación interna a partir de estas resistencias? Restan las palabras al enfrentarse con las declaraciones de su secretario general que se transcriben a continuación:

A raíz del ataque de la UTA, su secretario general, Roberto Fernández, dijo que el

sobre la producción, educando a toda la masa obrera para la lucha revolucionaria y por la creación del Estado obrero" (Gramsci, 1920: 5). sindicato "no avala la huelga declarada por un minúsculo grupo (los delegados), al que nada le importan los trabajadores' (Diario La Nación, 13/12/06).

Recuperando los presupuestos de los teóricos de la renovación sindical sobre modernización de las estructuras, se considera importante sumar un elemento más que surge de una de estas entrevistas:

- Nosotros estamos acostumbrados a que en los Sindicatos existan Secretarías que no tengan absolutamente ningún funcionamiento; por ejemplo en la UTA ¿cuáles son las actividades o reuniones? o ¿cuál es el funcionamiento real de la Secretaría de Cultura, o la de la Secretaría de Acción Social? Ninguna. Son secretarías que tienen un secretario cuya función es hacer lobby para uno $\mathrm{u}$ otro grupo de poder dentro del mismo Sindicato [...]Nuestra idea es llenar las Secretarías de compañeros, incluso con aquellos compañeros o conocidos que no trabajan en el Subte y que quieren cooperar (Delegado de Metrovías).

Se advierte que la AGTSyP reviste aún la frescura de la novedad, alejada de tradiciones anquilosadas y corruptas. No se puede afirmar que será ese su destino, o que por el contrario, sobrevendrá la burocratización. Sin embargo, esta construcción gremial opositora se ha planteado - al menos hasta el momento y con fuerte presencia en el espacio discursivo-, la horizontalidad y la democratización como pilares clave.

\section{COMENTARIOS FINALES}

Este artículo intenta introducir posibles dimensiones a un debate que está presente en la Argentina de los últimos años. La recomposición de la economía y la recuperación de los índices de empleo que se dieron desde fines de 2002, propiciaron el regreso a la escena pública del actor sindical. En ese marco, los sindicatos se constituyeron en un sujeto político a tener en cuenta a la hora de las negociaciones Estado- 
Capital-Trabajo y al mismo tiempo, recuperaron centralidad en las discusiones académicas.

En este contexto se sitúan los debates sobre revitalización sindical. Se repasó en estas páginas las principales características y los exponentes más resonantes a nivel internacional, con el objetivo de describir a qué se refieren estas teorizaciones al plantear una reactivación del sindicalismo. No obstante, el interés radica en analizar la recepción de esta cuestión en Argentina, cuya particularidad pretende hacer inteligible.

Tras la lectura de estos textos, resonaba un interrogante que impulsó a escribir esta contribución: ¿qué potencialidades analíticas reviste la idea de revitalización sindical? Con el objeto de acercarse a alguna suerte de respuesta a esta pregunta, se decide reflexionar a partir de un caso empírico: la experiencia de organización de los trabajadores de subterráneos. Se dedicó unas páginas a describir el proceso de conformación de ese colectivo sindical opositor para precisamente visibilizar esa particularidad, su relación con la UTA.

El lector podrá constatar que ciertamente esta es una expresión de revitalización sindical. La pregunta surge pues, cuando se advierte que con el mismo concepto son descriptas todas las experiencias de reactivación sindical, fundamentalmente aquellas que tienen que ver con la recuperación de salarios y la firma de negociaciones colectivas a favor de los trabajadores. Muchas veces los sindicatos que llevan adelante esos procesos representan la expresión más burocratizada y alejada de los reclamos de los trabajadores - como en este caso la UTA- sin embargo, se los incluye dentro de la categoría de análisis de la reactivación. Entonces, la revitalización sindical puede indicar tanto la consolidación de un sindicalismo burocratizado, como la emergencia de organizaciones de base que, cuestionando el sistema vigente, pretenden disputarle el poder a esas estructuras.

Para finalizar se plantea cierta imprecisión en la utilización de la categoría de revitalización sindical. Resulta interesante y pertinente el concepto, pero se considera que debe ajustarse a cada realidad laboral, no solo para que la teoría y la empiria se asemejen lo más posible, sino también para que, en términos políticos, pueda ser utilizada por los trabajadores como herramienta para la transformación.

\section{BIBLIOGRAFÍA CITADA}

Abal Medina, P. "Dispositivos de poder en empresas. Un estudio de la relación capital-trabajo en grandes empresas en grandes cadenas de supermercados". Serie Informes de Investigación CEILPIETTE CONICET 124. Buenos Aires, 2006.

Abal Medina, P.; Arias, C.; Crivelli, K. y Diana Menéndez, N. "Las configuraciones del conflicto laboral en empresas de servicios. Un estudio de casos en call centersy subtes”.e-l@tina.Revista electrónica de estudios latinoamericanos 6 (23). Buenos Aires, 2008: 39-57.

Arias, C. $y$ Haidar, V. "Resistir en nombre de la salud. Un análisis de la experiencia del Cuerpo de delegados de los subterráneos de la ciudad de Buenos Aires". Revista Trabajo y Sociedad 11. Santiago del Estero. Argentina: UNSE, 2008.

Arias, C. y Salgado, P. “De qué hablamos cuando hablamos de sindicalismo? Aportes para problematizar esta cuestión a la luz de la experiencia de los trabajadores de subterráneos". Ponencia presentada en $5^{\circ}$ Jornadas de Jóvenes Investigadores. Publicación completa en CD (ISBN: 978-950-29-1180-9). Instituto de Investigaciones Gino Germani, Facultad de Ciencias Sociales, Universidad de Buenos Aires. Noviembre de 2009.

Atzeni, M. y Ghigliani, P. "The resilience of traditional trade union practices in the revitalisation of the Argentine labour movement". Phelan, C. (ed.). Trade union revitalisation: trends and prospects in 34 countries. lera edición. Oxford: Peter Lang, 2007.

Atzeni, M. y Ghigliani, P. "Nature and limits of trade unions' mobilisations in contemporary Argentina". LabourAgain Publications. Amsterdam: IISG, marzo 2008.

Baccaro, L.; Hamann, K. y Turner, L. "The politics of labour movement 
revitalization: the need for a revitalized perspective". European Journal of Industrial Relations 9. 2003: 119-133.

Etchemendy, S. y Collier, R. "Golpeados pero de pie: resurgimiento sindical $y$ neocorporativismo segmentado en Argentina (2003-2007)". Politics and Society 35 (3). 2007: 363-401.

Fairbrother, P. et ál. "Unions facing the future: questions and possibilities". Labor Studies Journal 31. 2007: 31-53.

Fiorito, J. "Union renewal and the organizing model in the United Kingdom". Labor Studies Journal 29. 2004: 21-53.

Foucault, M. "El sujeto y el poder". 1983. [En línea]. En: <http://www.campogrupal. com/poder.html> [consultado el 15-509].

Gall, G. "What is to be done with union organising?". Gall, G. (ed.). Union revitalisation in advanced economies: assessing the contribution of union organising. lera edición. Inglaterra: Palgrave Macmillan, 2009.

Gramsci, A. "El consejo de fábrica"; "Sindicatos $y$ consejos"; "El movimiento turinés de los consejos de fábrica"; "El programa de L'Ordine Nuevo". Escritos 1917-1922. [Libro en línea]. En: <www.gramsci.org> [consultado el 20-7-08].

Haidar, J. "Revitalización sindical en Argentina $¿$ Sindicalismo de movimiento social o neocorporativismo segmentado?". Ponencia presentada en el $27^{\circ}$ Congreso de la Asociación Latinoamericana de Sociología (ALAS). Buenos Aires, 2009.

Haiven, L. "Expanding the union zone: union renewal through alternative forms of worker organization". Labor Studies Journal 31. 2006: 85-116.

Hamann, K. y Martínez Lucio, M. "Strategies of union revitalization in Spain: negotiating change and fragmentation". European Journal of Industrial Relations 9. 2003: 61-78.

Phelan, C. "Worldwide trends and prospects for trade union revitalisation". Phelan, C. (ed.). Trade union revitalisation: trends and prospects in 34 countries. 1era edición. Oxford: Peter Lang, 2007.

Santella, A. "Reactivación de los conflictos en el sector automotriz argentino, 2004-2006". LabourAgain Publications. Amsterdam: IISG, marzo 2008.

Vocos, F. "Enfrentando la ofensiva empresaria: la construcción del anteproyecto de convenio colectivo por los trabajadores de subte". Ponencia presentada en VIII Congreso de la Asociación Argentina de Especialistas en Estudios del Trabajo. Buenos Aires, 2007.

\section{OTRAS FUENTES}

Diario La Nación.

Entrevistas en profundidad realizadas a trabajadores $y$ delegados realizadas en el período 2006-2009.

Página web de metrodelegados. En:< http:// www.metrodelegados.com.ar/> [consultada el 8-10-08].

Fecha de ingreso: 21/12/2010

Fecha de aprobación: 31/03/2011 
